\title{
HTLV-1 bZIP factor: the key viral gene for pathogenesis
}

\author{
Masao Matsuoka ${ }^{1,2^{*}}$ (i) and Jean-Michel Mesnard ${ }^{3 *}$
}

\begin{abstract}
Human T cell leukemia virus type 1 (HTLV-1) causes adult T-cell leukemia-lymphoma (ATL) and inflammatory diseases. The HTLV-1 bZIP factor (HBZ) gene is constantly expressed in HTLV-1 infected cells and ATL cells. HBZ protein suppresses transcription of the tax gene through blocking the LTR recruitment of not only ATF/CREB factors but also CBP/p300. HBZ promotes transcription of Foxp3, CCR4, and T-cell immunoreceptor with Ig and ITIM domains (TIGIT). Thus, HBZ is critical for the immunophenotype of infected cells and ATL cells. HBZ also functions in its RNA form. HBZ RNA suppresses apoptosis and promotes proliferation of T cells. Since HBZ RNA is not recognized by cytotoxic T cells, HTLV-1 has a clever strategy for avoiding immune detection. HBZ plays central roles in maintaining infected T cells in vivo and determining their immunophenotype.
\end{abstract}

Keywords: HTLV-1, HBZ, Viral oncogenesis, Regulatory T cell

\section{Background}

Complex retroviruses like Human T-cell leukemia virus type 1 (HTLV-1) harbor all three common retroviral genes (gag, pol, and env) in addition to both regulatory genes directly involved in regulation of viral expression and accessory genes. All these genes are expressed through transcripts initiating from the enhancer/promoter in $5^{\prime}$ Long Terminal Repeat (LTR) region. Furthermore, a crucial study published in 2002 demonstrated undeniably the existence of a negative-strand-encoded protein termed HBZ (HTLV-1 bZIP factor) [1] synthesized from antisense transcripts produced from the $3^{\prime}$ LTR [2-5]. Thereafter, it became evident that HBZ is the only viral gene conserved and expressed in adult T-cell leukemia-lymphoma (ATL) cells, indicating that HBZ plays critical roles in leukemogenesis [3]. In addition, HBZ is implicated in inflammatory diseases caused

\footnotetext{
*Correspondence: mamatsu@kumamoto-u.ac.jp; jean-michel.mesnard@irim.cnrs.fr

${ }^{1}$ Department of Hematology, Rheumatology and Infectious Diseases, Faculty of Life Sciences, Kumamoto University, Kumamoto 860-8556, Japan

${ }^{3}$ IRIM, Université de Montpellier, CNRS, Montpellier, France

Full list of author information is available at the end of the article
}

by HTLV-1 like HTLV-1-associated myelopathy/tropical spastic paraparesis (HAM/TSP). In this review, we summarize what is known about HBZ and discuss its significance in pathogenesis by HTLV-1.

\section{Transcriptional control of the $\boldsymbol{h b z}$ gene}

Expression of the $h b z$ gene is regulated by a bidirectional promoter located in the $3^{\prime}$ LTR [5-7]. It is noteworthy that all retroviral LTRs examined to date contain bidirectional promoters [7-12]. For HTLV-1, deletion mutants and point mutation experiments have revealed the importance of three Sp1-binding sites to be essential for antisense promoter regulation [5, 7]. Sp1 allows transcription to initiate from TATA-less promoters, and in fact HTLV-1 antisense transcripts initiate from multiple positions due to the absence of TATA boxes $[3,4]$.

A positive effect of Tax (HTLV-1 trans-activator) on antisense transcription has been suggested, based on data that were obtained from cells transfected with reporter vectors containing only one LTR $[5,7,13]$. On the other hand, results were totally different when analyzing sense and antisense transcription from viral constructs containing both LTRs: Tax did not activate antisense transcription from the $3^{\prime}$ LTR in this case [14]. Interestingly,

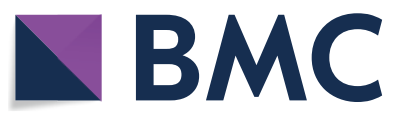

c) The Author(s) 2020. This article is licensed under a Creative Commons Attribution 4.0 International License, which permits use, sharing, adaptation, distribution and reproduction in any medium or format, as long as you give appropriate credit to the original author(s) and the source, provide a link to the Creative Commons licence, and indicate if changes were made. The images or other third party material in this article are included in the article's Creative Commons licence, unless indicated otherwise in a credit line to the material. If material is not included in the article's Creative Commons licence and your intended use is not permitted by statutory regulation or exceeds the permitted use, you will need to obtain permission directly from the copyright holder. To view a copy of this licence, visit http://creativecommons.org/licenses/by/4.0/. The Creative Commons Public Domain Dedication waiver (http://creativecommons.org/publicdomain/zero/1.0/) applies to the data made available in this article, unless otherwise stated in a credit line to the data. 
transfection of a $5^{\prime}$ LTR-deleted proviral clone into 293T cells stimulates synthesis of antisense transcripts from the $3^{\prime}$ LTR [4], suggesting that decreased sense transcription may indeed result in an increased antisense transcription. This buildup of $h b z$ mRNA in response to sense transcript decay has also been observed in short-term cultures of freshly isolated $\mathrm{CD}^{+}{ }^{+} \mathrm{T}$ cells from HAM/TSP patients [15]. Conversely, analysis of viral protein expression in HTLV-1-infected T-cell lines confirmed very low HBZ levels in cells expressing elevated amounts of Gag $[16,17]$. Taken together, all these observations suggest that Tax could indirectly keep antisense transcription to low levels through its stimulation of sense transcription and viral production. Studies performed using an in vivo rabbit model came to a similar conclusion. In HTLV1-infected rabbits, entry into the chronic stage of infection coincides with the loss of Tax and Gag production, while HBZ expression is maintained at a steady state [16]. These results confirm an inverse correlation between sense and antisense transcription, and between Tax/Gag and HBZ expression, suggesting that HTLV-1 may use HBZ for the establishment of chronic infection [18].

\section{HBZ suppresses sense transcription}

HBZ could be essential for maintaining latency in infected cells, likely by down-regulating viral expression from the $5^{\prime}$ LTR $[1,18-20]$. The HTLV-1 LTR contains three viral cyclic AMP response elements (vCREs) allowing for transcription transactivation by Tax; the viral transactivator does not specifically bind to vCRE sites but instead interacts with cellular ATF/ CREB factors like CREB and CREB-2 (Fig. 1) [21-26]. These transcription factors contain both a leucine zipper (ZIP) domain involved in protein dimerization and a basic region (immediately preceding the ZIP domain) required for their binding to the CRE site. After binding to the LTR vCREs, the Tax/CREB complex recruits the cellular coactivator CREB-binding protein (CBP) or its paralogue p300 to the viral promoter [21-26]. Once CBP or p300 is associated with the promoter, it bridges interactions between the Tax/CREB complex and the general transcription factor/RNA polymerase II complex. Additionally, both CBP and p300 possess a histone acetyltransferase (HAT) domain that plays an essential role in transcriptional activation by

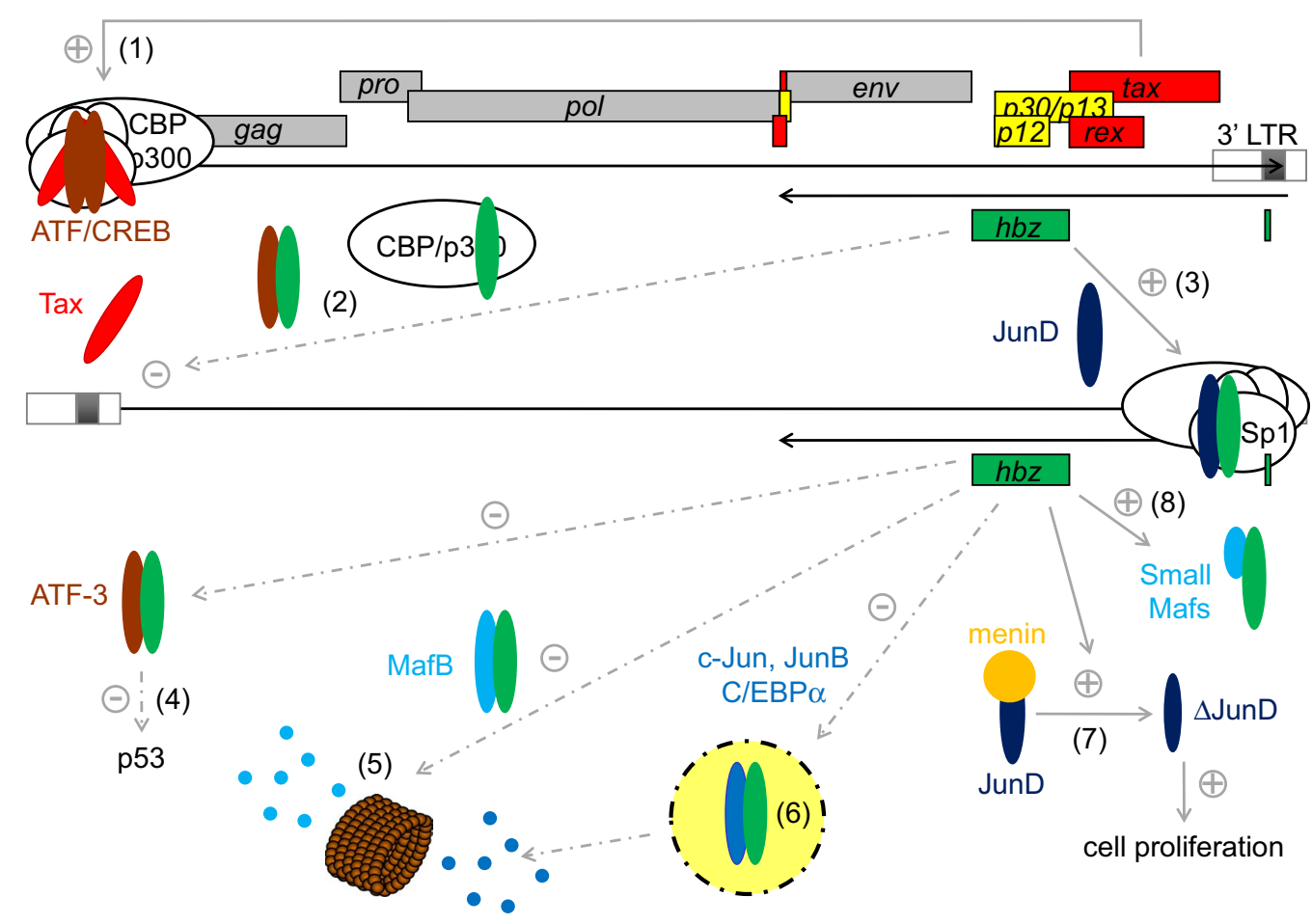

Fig. 1 Effect of HBZ on bZIP factor activities. (1) Tax interacts with CREB to bind to vCREs and then recruits CBP (or p300) to activate viral transcription from the 5' LTR. (2) HBZ inhibits Tax-dependent viral transcription by interacting with CREB and CBP/p300. (3) HBZ also stimulates its own expression by forming HBZ/JunD heterodimers capable of interacting with Sp1 bound to the $3^{\prime}$ LTR. (4) HBZ can also bind to ATF-3/p53 complexes, reducing ATF3's ability to enhance p53 activity. (5 and 6) HBZ inhibits the MafB, C/EBPa, c-Jun, and JunB transcriptional activities by promoting their degradation via a proteasome-dependent pathway (5) or by sequestration into nuclear bodies (6). HBZ stimulates JunD activity (7) by inducing expression of $\triangle J U n D$, a JunD isoform that is unable to interact with the inhibitor menin. HBZ is also able to activate HMOX1 transcription by forming heterodimers with the small Mafs [42] 
mediating acetylation of promoter-concealing nucleosomal histones.

Interestingly, a yeast two-hybrid screening of an HTLV1-infected T-cell cDNA bank using the CREB-2 bZIP domain as bait successfully identified HBZ, which was shown to inhibit Tax-dependent viral transcription by interacting with CREB-2 and inhibiting the binding of CREB-2 to the vCREs [1]. An equivalent negative effect of HBZ has also been described for other ATF/CREB factors like CREB, CREM, and ATF-1 [19]. Thus, even if Tax expression were higher than HBZ expression in HTLV-1 infected cells, HBZ would block the formation of an active transcriptional complex on the viral promoter by specifically targeting these cellular factors. However, it has also been suggested that HBZ could be insufficient to block Tax activity in HTLV-1-infected cells expressing Tax strongly [27].

Interestingly, HBZ and Tax have opposite effects on many signaling pathways [28]. HBZ suppresses the NFkB, NFAT, and AP-1 pathways, whereas Tax can activate them. Conversely, HBZ activates the TGF- $\beta /$ Smad pathway while Tax inhibits it. This reciprocal expression pattern could also fine-tune these signaling pathways, leading to the survival and proliferation of infected cells.

\section{HBZ structure and interaction with CBP/p300}

Two isoforms of HBZ (206 and 209 residue-long proteins) have been characterized, but differences in their amino acid sequences are restricted to a small region at their N-termini and are not believed to cause major discrepancies in protein function $[4,5]$. Indeed, the polypeptide domains involved in the transcription regulation function of HBZ are well conserved in both isoforms [8]. First, HBZ possesses an $\mathrm{N}$-terminal activation domain containing two LxxLL-like motifs that interact directly with the KIX domain of CBP/p300 that is also recognized by Tax [20]. By interacting with these co-activators, HBZ interferes with Tax's ability to interact with CBP/ p300 and thus prevents their recruitment to the viral promoter (Fig. 1). Therefore, HBZ has a bipartite mechanism of repressing Tax-dependent HTLV-1 transcription activation: HBZ blocks the LTR recruitment of not only ATF/CREB factors but also CBP/p300. Moreover, HBZ interacts with other $\mathrm{CBP} / \mathrm{p} 300$ domains, including both the HAT and $\mathrm{C} / \mathrm{H} 3$ domains [29]. These interactions inhibit the HAT activity of p300/CBP, causing a reduction in p53 acetylation and a repression of p53 activity [30]. HBZ also contains three basic regions in its central portion that mediate its nuclear localization [31]. However, while HBZ was found in the nucleus in ATL cells [32], HBZ would localize exclusively in the cytoplasm of infected cells in asymptomatic carriers and HAM/TSP patients [33]. Finally, its C-terminal region encompasses a bZIP domain that plays a key function in regulating the activity of several bZIP factors. This domain is subdivided into a basic region involved in DNA-binding and a ZIP that forms coiled-coil interactions with similar domains found in other bZIP transcription factors like CREB and CREB-2 [1, 19], ATF-1, -2, and -3 [34, 35], C/ EBP $\alpha$ and $\gamma[35,36]$, MafB [37], c-Jun and JunB [31, 38, 39]. The basic region of the HBZ bZIP domain diverges from corresponding regions in cellular bZIP factors [40], and consequently, heterodimerization between HBZ and these factors inhibits their association with cellular promoters $[36-39,41]$. On the other hand, HBZ has recently been reported to activate transcription of the Heme Oxygenase 1 (HMOX1) gene by interacting with the small Mafs (MafF, MafG, or MafK) at Maf responsive elements located in an enhancer upstream of $H M O X 1$ [42]. Small Mafs differ from MafB in that they lack activation domain but they could form a complex capable of recruiting $\mathrm{CBP} / \mathrm{p} 300$ by binding to $\mathrm{HBZ}$ [42].

\section{HBZ and the AP-1 family}

Among these cellular bZIP-containing transcription factors, HBZ specifically targets members of the Jun (Jun, JunB and JunD) family; these factors, together with members of the Fos, ATF/CREB and Maf families, all belong to the activating protein-1 (AP-1) transcription factor family. The central role of the AP-1 family in cellular transcriptional regulation turns it into a epicenter of pathological signal relay in diseases, particularly in the context of leukemia and lymphoma [43, 44]. Several groups have reported that in fresh ATL cells, AP-1 was strongly deregulated $[17,45]$. Among the Jun family members, JunD is highly expressed in ATL cells, while c-Jun expression is maintained at an undetectable level. Interestingly, HBZ is able to inhibit c-Jun activity (Fig. 1) both by sequestrating it into transcriptionally inactive nuclear bodies and by promoting its degradation via a proteasome-dependent pathway [39, 46]. Meanwhile, HBZ interacts with JunD to stimulate its own expression from the viral $3^{\prime}$ LTR (Fig. 1), as well as the transcription of cellular genes such as hTERT [6, 47]. By ChIP assays, it has been demonstrated that Sp1 transcription factors bound to the $3^{\prime}$ LTR or to the hTERT promoter act as docking sites for the heterodimer HBZ-JunD to stimulate gene expression.

JunD has been primarily thought of as a growth suppressor only because menin, a broadly expressed tumor suppressor, inhibits JunD transcriptional activity by interacting with its N-terminal domain [48]. In the absence of menin, JunD switches from a growth suppression to a growth promotion activity [49]. We have recently found that JunD could also promote proliferation and cell transformation when associated with HBZ [6, 17]. In addition, 
the intronless mRNA of jund can generate two protein isoforms using alternative translation initiation sites: fulllength JunD (JunD-FL) and $\Delta$-JunD, an N-terminal truncated form of JunD-FL, unable to interact with menin. $\mathrm{HBZ}$ is able to stimulate $\Delta$-JunD translation by depleting the ribosomal protein S25 [17] and thus can potentially mediate a shift from the JunD-FL-induced suppression of cell proliferation to promoting proliferation by stimulating $\Delta$-JunD synthesis (Fig. 1).

\section{HTLV-1 infected cells and ATL cells maintain the $H B Z$ gene}

The HTLV-1 provirus is the only direct evidence of infection in ATL cells. Therefore, the analysis of HTLV-1 provirus in ATL cells provides us important information on leukemogenesis [50]. Transcription of tax is frequently undetectable in ATL cases. There are three mechanisms that inactivate Tax expression: (1) deletion of the 5'LTR [51, 52], (2) DNA methylation of the 5'LTR [53, 54 ], and 3) genetic changes (non-sense mutations, deletions or insertions) within the $\operatorname{tax}$ gene $[55,56]$. Tax is not expressed in approximately half of ATL cases [57]. However, the pX region and the $3^{\prime} \mathrm{LTR}$, which together contain the promoter and the coding region of the $H B Z$ gene, remain intact in all ATL cases. Indeed, the $H B Z$ gene is transcribed in all ATL cases [3]. In addition, the knock-down of HBZ suppresses the proliferation of ATL cells, indicating that the $H B Z$ gene is critical for leukemogenesis $[3,58,59]$.

When during the course of ATL leukemogenesis is Tax expression inactivated? Among genetic changes of the $\operatorname{tax}$ gene in ATL cells, non-sense mutations are the most frequently detected. Importantly, most non-sense mutations are found in TGG (methionine) codons, which are also the target sequences of APOBEC3G [56]. APOBEC3G targets single stranded DNA during reverse transcription and generates non-sense mutations in the provirus. Indeed, non-sense mutations of the tax gene are also found in the provirus of asymptomatic carriers, which indicates that these non-sense mutations are generated before proviral integration. Since most infected cells have only one copy of the provirus [60], ATL cells with non-sense mutations in the $\operatorname{tax}$ gene must have become transformed without Tax.

A similar important finding is that in some ATL cases, the $5^{\prime}$ LTR is lost before integration. HTLV-1 integrase generates 6 bp short repeats at the $5^{\prime}$ and $3^{\prime}$ ends of the provirus. In some ATL cases without the $5^{\prime} \mathrm{LTR}$, this short repeat is connected to an internal sequence ( $p o l$ and $e n v$ ) of the provirus, and the $3^{\prime} \mathrm{LTR}$, suggesting that viral integrase sometimes recognizes an internal sequence and the $3^{\prime}$ LTR, and then integrates a defective provirus into the host genome [52]. Again, this shows that Tax expression can be lost before integration. The $3^{\prime}$ LTR and HBZ coding region remain intact even in these defective proviruses in ATL cases, suggesting that in these cases, ATL may develop in the presence of $\mathrm{HBZ}$ alone.

\section{How HBZ modulates infected cells}

The receptor for HTLV-1 is glucose transporter 1 (GLUT-1), neuropilin and heperan sulfate proteoglycan, which are expressed on a variety of cells. Indeed, HTLV-1 can infect many different types of cells, suggesting that infection itself does not define cell specificity. However, HTLV-1 provirus is detected mainly in CD $4+\mathrm{T}$ cells in vivo [61]. Furthermore, the immunophenotype of most HTLV-1 infected cells is CD4+CD45RO + CD25 + CCR $4+$ CADM1 + . Foxp3 is frequently expressed in HTLV-1 infected cells and ATL cells [62]. Thus, this virus targets a limited subpopulation of CD4+T cells in vivo. Since this observation is not consistent with the findings that HTLV-1 can infect many different types of cells in vitro, it appears that HTLV-1 modulates the immunophenotypes of infected cells and/or promotes the proliferation of specific kinds of $\mathrm{CD} 4+\mathrm{T}$ cells.

It has been reported that HTLV-1 infects hematopoietic stem cells in the bone marrow, since identical integration sites of HTLV-1 provirus were identified in different hematopoietic cells [63]. One speculates that infected cells differentiate into various hematopoietic cells including $\mathrm{T}$ cells, B cells, monocytes, and neutrophils. HTLV-1 infection to immature cells was also suggested by the report that ATL clones with the identical integration site of the provirus and different $\mathrm{T}$-cell receptor gene rearrangement were found in the same patients [64]. It is possible that viral gene(s) modulate the differentiation of infected cells. Since only HBZ is constantly expressed in infected cells, it is thought that HBZ must modulate this differentiation, increasing the population of infected CD4 $\mathrm{T}$ cells with specific markers. As mechanisms, HBZ induces transcription of Foxp3, CCR4, and T-cell immunoreceptor with Ig and ITIM domains (TIGIT) in vitro and in vivo (Fig. 2).

Why does HBZ convert infected cells to cells with such specific immunophenotypes? One possibility is that effector/memory $\mathrm{T}$ cells tend to enter breast milk and semen [28]. Since HTLV-1 transmits mainly through breast feeding and sexual intercourse, producing a large number of infected cells with this immunophenotype is critical for the transmission of HTLV-1 [65]. Another reason is to evade host immune responses. Foxp3 can induce expression of immunosuppressive molecules, including CTLA-4, GITR, IL-35 and IL-10. Presumably, HTLV-1 infected T cells that are Foxp3 + would tend to escape from host immune surveillance. Indeed, HTLV-1 provirus is detected in Foxp3 $+\mathrm{CD} 4+\mathrm{T}$ cells in carriers. 


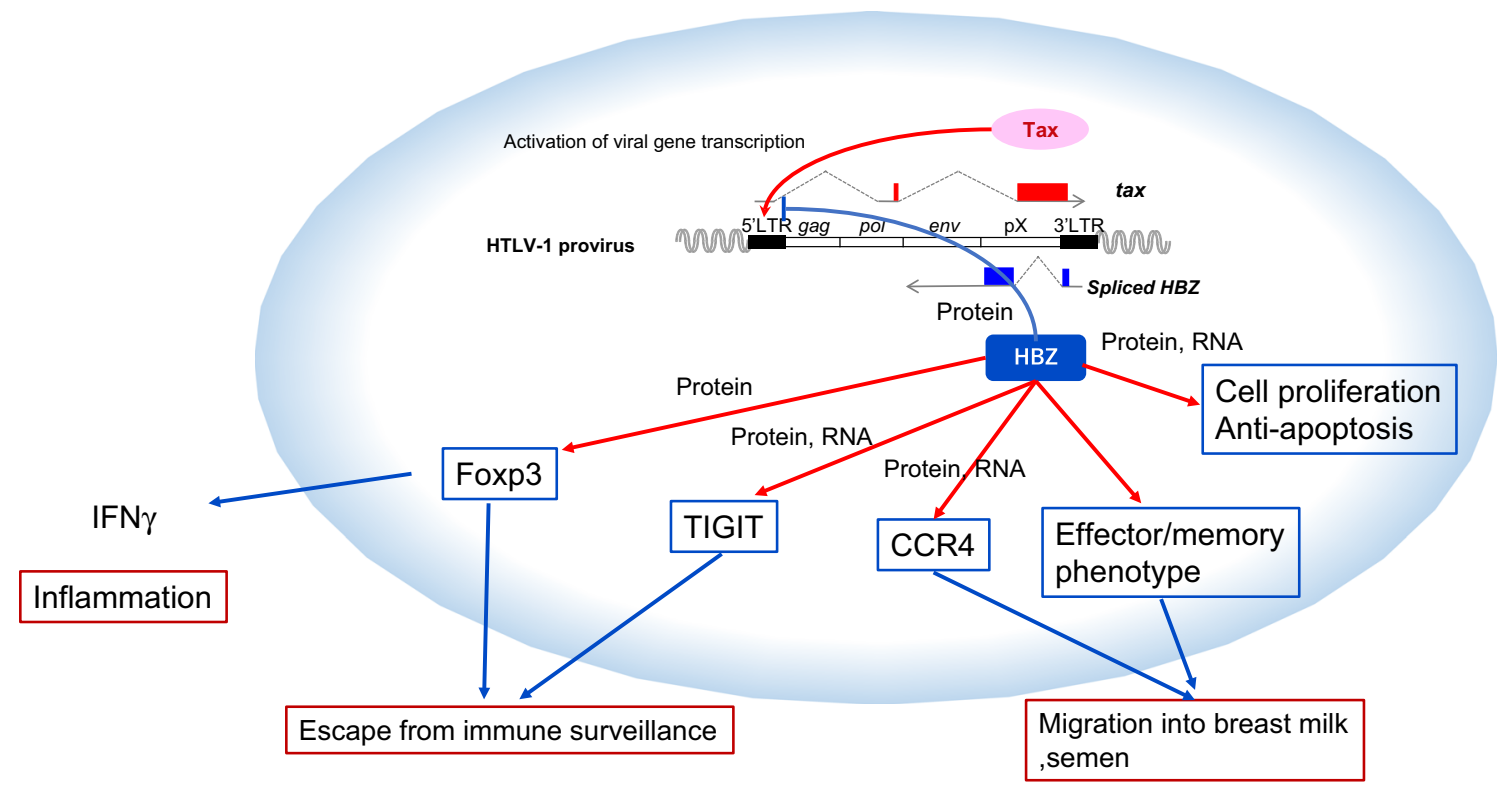

Fig. 2 Functions of HBZ. HBZ induces transcription of Foxp3, CCR4 and TIGIT genes. HBZ expression promotes the proliferation of T cells and inhibits their apoptosis. In addition, HBZ changes expressing T cells to an effector/memory phenotype, which is important for their migration into breast milk and semen

\section{Function of $H B Z$ RNA}

Not only HBZ protein, but also $H B Z$ RNA promotes the proliferation of infected cells. An $H B Z$ mutant (TTG mutant), in which the first ATG is replaced by TTG, cannot produce the HBZ protein [3]. Interestingly, this TTG mutant still promotes the proliferation and inhibits the apoptosis of expressing $\mathrm{T}$ cells, implicating $H B Z$ RNA in cell proliferation and ATL [66]. This function of $H B Z$ RNA is particularly beneficial for HTLV-1 infected cells and ATL cells, because RNA is not recognized by the host immune surveillance. In the case of Epstein-Barr virus (EBV), it has been reported that EBV encoded small RNA (EBER) contributes to oncogenesis by modulating innate immunity [67]. Thus, functional viral RNA is thought to be clever strategy by which chronic viral infections evade host immune surveillance.

Tax is intermittently expressed in ATL cell lines and HTLV-1 infected cell lines [68]. This intermittent expression is associated with resistance to apoptosis. HBZ is also reported to be expressed in a part of HTLV-1 infected cells in contrast to ATL cell lines [69], in which $H B Z$ is expressed in almost all cells. Level of $H B Z$ transcripts, but not tax, is correlated with the $S$ and G2/M phases of the cell cycle [69], suggesting that HBZ RNA, but not tax, is linked with cell proliferation [66].

\section{Implication of HBZ in leukemogenesis}

In vivo expression of $H B Z$ in transgenic mice causes T-cell lymphomas and inflammatory diseases [70]. Interestingly, $\operatorname{tax}$ transgenic mice in which $\operatorname{tax}$ is expressed in $\mathrm{CD} 4+\mathrm{T}$ cells did not develop any such diseases [71]. Furthermore, Tax is not expressed in approximately half of ATL cases due to genetic changes of the $\operatorname{tax}$ gene, DNA methylation of $5^{\prime}$ LTR and deletion of $5^{\prime}$ LTR [50]. Importantly, non-sense mutations of the tax gene, and half of $5^{\prime}$ LTR deletion are generated at infection of HTLV-1, suggesting that tax gene is not necessary for leukemogenesis in these cases $[52,56]$. These findings suggest that HBZ, but not tax, is mainly implicated in pathogenesis by HTLV-1. Tax might play an important role in half of ATL cases since they retain capability to express Tax, and transient Tax expression is critical for survival of ATL cells [68]. In addition, HBZ induces genetic instability in expressing cells [72, 73], suggesting that HBZ promotes leukemogenesis by induced genetic instability.

A recent study using screening by gene knockout with the CRISPR/Cas9 system reported that IRF4 and BATF3 are critical for the growth of ATL cells [59]. HBZ protein upregulates the expression of BATF3. Mutation of IRF4 is also reported to be associated with poor prognosis for ATL patients [74]. Thus, HBZ appears to be responsible for leukemogenesis of ATL. 
Comprehensive studies of genetic and epigenetic changes in ATL cells revealed that multiple alterations are identified in genes associated with T-cell receptorNFkB signaling, T-cell tracking, other T-cell related pathways and immunosurveillance [75]. These pathways are also influenced by HBZ. In the carrier state, only the $H B Z$ gene is constantly expressed, and ATL develops in the absence of Tax. But most infected cells do not become leukemic. Therefore, it is thought that genetic and epigenetic changes must potentiate or fix the effects of HBZ, leading to the development of ATL.

$H B Z$ RNA is implicated in proliferation of ATL cells and HTLV-1 infected cells [3, 66]. Effects of HBZ protein and mRNA differ in cellular signaling pathways. $H B Z$ RNA promotes cell proliferation and suppresses apoptosis whereas HBZ protein increases apoptosis [66]. However, both $H B Z$ RNA and the protein induces expression of CCR4 and TIGIT. Thus, detailed function of $\mathrm{HBZ}$ RNA and the protein should be studied in the future.

\section{Future direction of $\mathrm{HBZ}$ research}

It is becoming clear that HBZ plays several central roles in pathogenesis by HTLV-1. It is assumed that the pleiotropic functions of HBZ reflect a viral strategy that optimizes cell-to-cell transmission. The immunophenotypes of effector/memory $\mathrm{T}$ cells and Tregs are manipulated to allow the migration of infected cells into breast milk and semen-a phenomenon that also confers an infiltrative phenotype to ATL cells. However, questions remain about how HBZ RNA functions and how HBZ transforms $\mathrm{T}$ cells. In addition, there is the hope that immunotherapy against HBZ might improve the prognosis of ATL patients.

\section{Abbreviations \\ HTLV-1: human T-cell leukemia virus type 1; ATL: adult T-cell leukemia-lym- phoma; HBZ: HTLV-1 bZIP factor; TIGIT: T-cell immunoreceptor with Ig and ITIM domains; LTR: long terminal repeat; HAM/TSP: HTLV-1-associated myelopathy/ tropical spastic paraparesis; vCREs: viral cyclic AMP response elements; CBP: CREB-binding protein; HAT: histone acetyltransferase; GLUT-1: glucose trans- porter 1; EBV: Epstein-Barr virus; EBER: EBV encoded small RNA.}

\section{Acknowledgements}

We appreciate Linda Kingsbury for proof-reading of this manuscript.

\section{Authors' contributions}

MM, JM wrote the review. MM, and JM were involved in discussions and critical reading of the manuscript. Both authors read and approved the final manuscript.

\section{Funding}

This study was supported by the Project for Cancer Research And Therapeutic Evolution (P-CREATE) (17cm0106306h0002 to M.M.), the Research Program on Emerging and Re-emerging Infectious Diseases (17fk0108227h0002 to M.M.) from Japan Agency for Medical Research and development (AMED), JSPS KAKENHI (JP16H05336 to M.M.). This study was also supported in part by the JSPS Core-to-Core Program A, Advanced Research Networks.
Availability of data and materials

Not applicable.

Ethics approval and consent to participate

Not applicable.

\section{Consent for publication}

Not applicable.

\section{Competing interests}

The authors declare that they have no competing interests.

\section{Author details \\ ${ }^{1}$ Department of Hematology, Rheumatology and Infectious Diseases, Faculty of Life Sciences, Kumamoto University, Kumamoto 860-8556, Japan. ${ }^{2}$ Labora- tory of Virus Control, Institute for Frontier Life and Medical Sciences, Kyoto University, 53 Shogoin Kawahara-cho, Sakyo-ku, Kyoto 606-8507, Japan. ${ }^{3}$ IRIM, Université de Montpellier, CNRS, Montpellier, France.}

Received: 18 July 2019 Accepted: 2 January 2020

Published online: 08 January 2020

\section{References}

1. Gaudray G, Gachon F, Basbous J, Biard-Piechaczyk M, Devaux C, Mesnard JM. The complementary strand of the human T-cell leukemia virus type 1 RNA genome encodes a bZIP transcription factor that down-regulates viral transcription. J Virol. 2002;76(24):12813-22.

2. Larocca D, Chao LA, Seto MH, Brunck TK. Human T-cell leukemia virus minus strand transcription in infected T-cells. Biochem Biophys Res Commun. 1989;163:1006-13.

3. Satou Y, Yasunaga J, Yoshida M, Matsuoka M. HTLV-I basic leucine zipper factor gene mRNA supports proliferation of adult T cell leukemia cells. Proc Natl Acad Sci USA. 2006;103(3):720-5.

4. Cavanagh MH, Landry S, Audet B, Arpin-Andre C, Hivin P, Pare ME. HTLV-I antisense transcripts initiating in the $3^{\prime}$ LTR are alternatively spliced and polyadenylated. Retrovirology. 2006;3:15.

5. Yoshida M, Satou Y, Yasunaga J, Fujisawa J, Matsuoka M. Transcriptional control of spliced and unspliced human T-cell leukemia virus type 1 bZIP factor (HBZ) gene. J Virol. 2008;82(19):9359-68.

6. Gazon H, Lemasson I, Polakowski N, Cesaire R, Matsuoka M, Barbeau B, Mesnard JM, Peloponese JM Jr. Human T-cell leukemia virus type 1 (HTLV1) bZIP factor requires cellular transcription factor JunD to upregulate HTLV-1 antisense transcription from the $3^{\prime}$ long terminal repeat. J Virol. 2012;86(17):9070-8.

7. Arpin-Andre C, Laverdure S, Barbeau B, Gross A, Mesnard JM. Construction of a reporter vector for analysis of bidirectional transcriptional activity of retrovirus LTR. Plasmid. 2014;74:45-51.

8. Barbeau B, Peloponese JM, Mesnard JM. Functional comparison of antisense proteins of HTLV-1 and HTLV-2 in viral pathogenesis. Front Microbiol. 2013;4:226

9. Barbeau B, Mesnard JM. Does chronic infection in retroviruses have a sense? Trends Microbiol. 2015;23(6):367-75.

10. Durkin K, Rosewick N, Artesi M, Hahaut V, Griebel P, Arsic N, Burny A, Georges M, Van den Broeke A. Characterization of novel Bovine Leukemia Virus (BLV) antisense transcripts by deep sequencing reveals constitutive expression in tumors and transcriptional interaction with viral microRNAs. Retrovirology. 2016;13(1):33

11. Rasmussen MH, Ballarin-Gonzalez B, Liu J, Lassen LB, Fuchtbauer A, Fuchtbauer EM, Nielsen AL, Pedersen FS. Antisense transcription in gammaretroviruses as a mechanism of insertional activation of host genes. J Virol. 2010;84(8):3780-8.

12. Briquet S, Richardson J, Vanhee-Brossollet C, Vaquero C. Natural antisense transcripts are detected in different cell lines and tissues of cats infected with feline immunodeficiency virus. Gene. 2001;267(2):157-64.

13. Landry S, Halin M, Vargas A, Lemasson I, Mesnard JM, Barbeau B. Upregulation of human T-cell leukemia virus type 1 antisense transcription by the viral tax protein. J Virol. 2009;83(4):2048-54. 
14. Laverdure S, Polakowski N, Hoang K, Lemasson I. Permissive sense and antisense transcription from the $5^{\prime}$ and $3^{\prime}$ long terminal repeats of human T-cell leukemia virus type 1. J Virol. 2016;90(7):3600-10.

15. Belrose G, Gross A, Olindo S, Lezin A, Dueymes M, Komla-Soukha I, Smadja D, Tanaka Y, Willems L, Mesnard JM, et al. Effects of valproate on Tax and HBZ expression in HTLV-1 and HAM/TSP T lymphocytes. Blood. 2011;118(9):2483-91.

16. Li M, Kesic M, Yin H, Yu L, Green PL. Kinetic analysis of human T-cell leukemia virus type 1 gene expression in cell culture and infected animals. J Virol. 2009;83(8):3788-97.

17. Terol M, Gazon H, Lemasson I, Duc-Dodon M, Barbeau B, Cesaire R, Mesnard JM, Peloponese JM Jr. HBZ-mediated shift of JunD from growth suppressor to tumor promoter in leukemic cells by inhibition of ribosomal protein S25 expression. Leukemia. 2017;31(10):2235-43.

18. Arnold J, Yamamoto B, Li M, Phipps AJ, Younis I, Lairmore MD. Enhancement of infectivity and persistence in vivo by $\mathrm{HBZ}$, a natural antisense coded protein of HTLV-1. Blood. 2006;107:3976-82.

19. Lemasson I, Lewis MR, Polakowski N, Hivin P, Cavanagh MH, Thebault S, Barbeau B, Nyborg JK, Mesnard JM. Human T-cell leukemia virus type 1 (HTLV-1) bZIP protein interacts with the cellular transcription factor CREB to inhibit HTLV-1 transcription. J Virol. 2007;81(4):1543-53.

20. Clerc I, Polakowski N, Andre-Arpin C, Cook P, Barbeau B, Mesnard JM, Lemasson I. An interaction between the human T cell leukemia virus type 1 basic leucine zipper factor (HBZ) and the KIX domain of p300/CBP contributes to the down-regulation of tax-dependent viral transcription by HBZ. J Biol Chem. 2008;283(35):23903-13.

21. Kwok RP, Laurance ME, Lundblad JR, Goldman PS, Shih H, Connor LM, Marriott SJ, Goodman RH. Control of CAMP-regulated enhancers by the viral transactivator Tax through CREB and the co-activator CBP. Nature. 1996;380(6575):642-6.

22. Giebler HA, Loring JE, van Orden K, Colgin MA, Garrus JE, Escudero KW, Brauweiler A, Nyborg JK. Anchoring of CREB binding protein to the human T-cell leukemia virus type 1 promoter: a molecular mechanism of Tax transactivation. Mol Cell Biol. 1997;17(9):5156-64.

23. Lenzmeier BA, Giebler HA, Nyborg JK. Human T-cell leukemia virus type 1 Tax requires direct access to DNA for recruitment of CREB binding protein to the viral promoter. Mol Cell Biol. 1998;18(2):721-31.

24. Bex F, Yin MJ, Burny A, Gaynor RB. Differential transcriptional activation by human T-cell leukemia virus type 1 Tax mutants is mediated by distinct interactions with CREB binding protein and p300. Mol Cell Biol. 1998;18(4):2392-405.

25. Jiang H, Lu H, Schiltz RL, Pise-Masison CA, Ogryzko W, Nakatani Y, Brady JN. PCAF interacts with tax and stimulates tax transactivation in a histone acetyltransferase-independent manner. Mol Cell Biol. 1999;19(12):8136-45.

26. Harrod R, Kuo YL, Tang Y, Yao Y, Vassilev A, Nakatani Y, Giam CZ. p300 and p300/cAMP-responsive element-binding protein associated factor interact with human T-cell lymphotropic virus type-1 Tax in a multihistone acetyltransferase/activator-enhancer complex. J Biol Chem. 2000;275(16):11852-7.

27. Philip S, Zahoor MA, Zhi H, Ho YK, Giam CZ. Regulation of human T-lymphotropic virus type I latency and reactivation by HBZ and Rex. PLoS Pathog. 2014;10(4):e1004040.

28. Matsuoka M, Yasunaga J. Human T-cell leukemia virus type 1: replication, proliferation and propagation by Tax and HTLV-1 bZIP factor. Curr Opin Virol. 2013;3(6):684-91.

29. Wurm T, Wright DG, Polakowski N, Mesnard JM, Lemasson I. The HTLV1-encoded protein HBZ directly inhibits the acetyl transferase activity of p300/CBP. Nucleic Acids Res. 2012;40(13):5910-25.

30. Wright DG, Marchal C, Hoang K, Ankney JA, Nguyen ST, Rushing AW, Polakowski N, Miotto B, Lemasson I. Human T-cell leukemia virus type-1-encoded protein HBZ represses p53 function by inhibiting the acetyltransferase activity of p300/CBP and HBO1. Oncotarget. 2016;7(2):1687-706.

31. Hivin P, Frederic M, Arpin-Andre C, Basbous J, Gay B, Thebault S, Mesnard JM. Nuclear localization of HTLV-I bZIP factor (HBZ) is mediated by three distinct motifs. J Cell Sci. 2005:118(Pt 7):1355-62.

32. Raval GU, Bidoia C, Forlani G, Tosi G, Gessain A, Accolla RS. Localization, quantification and interaction with host factors of endogenous HTLV-1 HBZ protein in infected cells and ATL. Retrovirology. 2015;12:59.

33. Forlani G, Baratella M, Tedeschi A, Pique C, Jacobson S, Accolla RS. HTLV-1 HBZ protein resides exclusively in the cytoplasm of infected cells in asymptomatic carriers and HAM/TSP patients. Front Microbiol. 2019;10:819.

34. Hagiya K, Yasunaga J, Satou Y, Ohshima K, Matsuoka M. ATF3, an HTLV-1 bZip factor binding protein, promotes proliferation of adult T-cell leukemia cells. Retrovirology. 2011:8:19.

35. Reinke AW, Grigoryan G, Keating AE. Identification of bZIP interaction partners of viral proteins HBZ, MEQ, BZLF1, and K-bZIP using coiled-coil arrays. Biochemistry. 2010;49(9):1985-97.

36. Zhao T, Coutts A, Xu L, Yu J, Ohshima K, Matsuoka M. HTLV-1 bZIP factor supports proliferation of adult $T$ cell leukemia cells through suppression of C/EBPalpha signaling. Retrovirology. 2013;10:159.

37. Ohshima T, Mukai R, Nakahara N, Matsumoto J, Isono O, Kobayashi Y, Takahashi S, Shimotohno K. HTLV-1 basic leucine-zipper factor, HBZ, interacts with MafB and suppresses transcription through a Maf recognition element. J Cell Biochem. 2010;111(1):187-94.

38. Basbous J, Arpin C, Gaudray G, Piechaczyk M, Devaux C, Mesnard JM. The HBZ factor of human T-cell leukemia virus type I dimerizes with transcription factors JunB and c-Jun and modulates their transcriptional activity. J Biol Chem. 2003;278(44):43620-7.

39. Matsumoto J, Ohshima T, Isono O, Shimotohno K. HTLV-1 HBZ suppresses AP-1 activity by impairing both the DNA-binding ability and the stability of c-Jun protein. Oncogene. 2005;24:1001-10.

40. Hivin P, Arpin-Andre C, Clerc I, Barbeau B, Mesnard JM. A modified version of a Fos-associated cluster in HBZ affects Jun transcriptional potency. Nucleic Acids Res. 2006;34:2761-72.

41. Ma G, Yasunaga J, Fan J, Yanagawa S, Matsuoka M. HTLV-1 bZIP factor dysregulates the Wnt pathways to support proliferation and migration of adult T-cell leukemia cells. Oncogene. 2013;32(36):4222-30.

42. Rushing AW, Rushing B, Hoang K, Sanders SV, Peloponese JM Jr, Polakowski N, Lemasson I. HTLV-1 basic leucine zipper factor protects cells from oxidative stress by upregulating expression of heme oxygenase I. PLoS Pathog. 2019;15(6):e1007922.

43. Gazon H, Barbeau B, Mesnard JM, Peloponese JM Jr. Hijacking of the AP-1 signaling pathway during development of ATL. Front Microbiol. 2017:8:2686.

44. Papoudou-Bai A, Hatzimichael E, Barbouti A, Kanavaros P. Expression patterns of the activator protein-1 (AP-1) family members in lymphoid neoplasms. Clin Exp Med. 2017:17(3):291-304.

45. Nakayama T, Hieshima K, Arao T, Jin Z, Nagakubo D, Shirakawa AK, Yamada Y, Fujii M, Oiso N, Kawada A, et al. Aberrant expression of Fra-2 promotes CCR4 expression and cell proliferation in adult T-cell leukemia. Oncogene. 2008;27(23):3221-32.

46. Clerc I, Hivin P, Rubbo PA, Lemasson I, Barbeau B, Mesnard JM. Propensity for HBZ-SP1 isoform of HTLV-I to inhibit c-Jun activity correlates with sequestration of c-Jun into nuclear bodies rather than inhibition of its DNA-binding activity. Virology. 2009;391(2):195-202.

47. Kuhlmann AS, Villaudy J, Gazzolo L, Castellazzi M, Mesnard JM, Duc DM. HTLV-1 HBZ cooperates with JunD to enhance transcription of the human telomerase reverse transcriptase gene (hTERT). Retrovirology. 2007;4:92.

48. Agarwal SK, Guru SC, Heppner C, Erdos MR, Collins RM, Park SY. Menin interacts with the AP1 transcription factor JunD and represses JunDactivated transcription. Cell. 1999:96:143-52.

49. Agarwal SK, Novotny EA, Crabtree JS, Weitzman JB, Yaniv M, Burns AL, Chandrasekharappa SC, Collins FS, Spiegel AM, Marx SJ. Transcription factor JunD, deprived of menin, switches from growth suppressor to growth promoter. Proc Natl Acad Sci USA. 2003;100(19):10770-5.

50. Matsuoka M, Jeang KT. Human T-cell leukemia virus type 1 (HTLV-1) and leukemic transformation: viral infectivity, Tax. HBZ and therapy. Oncogene. 2010;30(12):1379-89.

51. Tamiya S, Matsuoka M, Etoh K, Watanabe T, Kamihira S, Yamaguchi K, Takatsuki K. Two types of defective human T-lymphotropic virus type I provirus in adult T-cell leukemia. Blood. 1996;88(8):3065-73.

52. Miyazaki M, Yasunaga J, Taniguchi Y, Tamiya S, Nakahata T, Matsuoka M. Preferential selection of human T-cell leukemia virus type 1 provirus lacking the $5^{\prime}$ long terminal repeat during oncogenesis. J Virol. 2007;81(11):5714-23.

53. Koiwa T, Hamano-Usami A, Ishida T, Okayama A, Yamaguchi K, Kamihira S, Watanabe T. 5'-long terminal repeat-selective CpG methylation of latent human T-cell leukemia virus type 1 provirus in vitro and in vivo. J Virol. 2002;76(18):9389-97. 
54. Taniguchi Y, Nosaka K, Yasunaga J, Maeda M, Mueller N, Okayama A, Matsuoka M. Silencing of human T-cell leukemia virus type I gene transcription by epigenetic mechanisms. Retrovirology. 2005;2:64

55. Furukawa Y, Kubota R, Tara M, Izumo S, Osame M. Existence of escape mutant in HTLV-I tax during the development of adult T-cell leukemia. Blood. 2001;97(4):987-93.

56. Fan J, Ma G, Nosaka K, Tanabe J, Satou Y, Koito A, Wain-Hobson S, Vartanian JP, Matsuoka M. APOBEC3G generates nonsense mutations in human T-cell leukemia virus type 1 proviral genomes in vivo. J Virol. 2010;84(14):7278-87.

57. Takeda S, Maeda M, Morikawa S, Taniguchi Y, Yasunaga J, Nosaka K, Tanaka Y, Matsuoka M. Genetic and epigenetic inactivation of tax gene in adult T-cell leukemia cells. Int J Cancer. 2004;109(4):559-67.

58. Arnold J, Zimmerman B, Li M, Lairmore MD, Green PL. Human T-cell leukemia virus type-1 antisense-encoded gene, $\mathrm{Hbz}$, promotes T-lymphocyte proliferation. Blood. 2008;112(9):3788-97.

59. Nakagawa M, Shaffer AL 3rd, Ceribelli M, Zhang M, Wright G, Huang DW Xiao W, Powell J, Petrus MN, Yang Y, et al. Targeting the HTLV-I-regulated BATF3/IRF4 transcriptional network in adult T cell leukemia/lymphoma. Cancer Cell. 2018;34(2):286-97.

60. Cook LB, Rowan AG, Melamed A, Taylor GP, Bangham CR. HTLV-1-infected $T$ cells contain a single integrated provirus in natural infection. Blood. 2012;120(17):3488-90.

61. Yasunaga J, Sakai T, Nosaka K, Etoh K, Tamiya S, Koga S, Mita S, Uchino M, Mitsuya H, Matsuoka M. Impaired production of naive T lymphocytes in human T-cell leukemia virus type l-infected individuals: its implications in the immunodeficient state. Blood. 2001;97(10):3177-83.

62. Satou Y, Utsunomiya A, Tanabe J, Nakagawa M, Nosaka K, Matsuoka M. HTLV-1 modulates the frequency and phenotype of FoxP3 + CD4 + T cells in virus-infected individuals. Retrovirology. 2012;9:46.

63. Furuta R, Yasunaga Jl, Miura M, Sugata K, Saito A, Akari H, Ueno T, Takenouchi N, Fujisawa Jl, Koh KR, et al. Human T-cell leukemia virus type 1 infects multiple lineage hematopoietic cells in vivo. PLoS Pathog. 2017;13(11):e1006722.

64. Rauch DA, Conlon KC, Janakiram M, Brammer JE, Harding JC, Ye BH, Zang $X$, Ren X, Olson S, Cheng X, et al. Rapid progression of adult T-cell leukemia/lymphoma as tumor-infiltrating Tregs after PD-1 blockade. Blood. 2019:134(17):1406-14

65. Tanaka A, Matsuoka M. HTLV-1 Alters T Cells for Viral Persistence and Transmission. Front Microbiol. 2018:9:461.
66. Mitobe Y, Yasunaga J, Furuta R, Matsuoka M. HTLV-1 bZIP factor RNA and protein impart distinct functions on T-cell proliferation and survival. Cancer Res. 2015;75(19):4143-52.

67. Takada K. Role of EBER and BARF1 in nasopharyngeal carcinoma (NPC) tumorigenesis. Semin Cancer Biol. 2012;22(2):162-5.

68. Mahgoub M, Yasunaga Jl, Iwami S, Nakaoka S, Koizumi Y, Shimura K, Matsuoka M. Sporadic on/off switching of HTLV-1 Tax expression is crucial to maintain the whole population of virus-induced leukemic cells. Proc Natl Acad Sci USA. 2018;115(6):E1269-78.

69. Billman MR, Rueda D, Bangham CRM. Single-cell heterogeneity and cell-cycle-related viral gene bursts in the human leukaemia virus HTLV-1. Wellcome Open Res. 2017;2:87.

70. Satou Y, Yasunaga J, Zhao T, Yoshida M, Miyazato P, Takai K, Shimizu K, Ohshima K, Green PL, Ohkura N, et al. HTLV-1 bZIP factor induces T-cell lymphoma and systemic inflammation in vivo. PLoS Pathog. 2011;7(2):e1001274

71. Zhao T, Satou Y, Matsuoka M. Development of T cell lymphoma in HTLV-1 bZIP factor and Tax double transgenic mice. Arch Virol. 2014;159(7):1849-56

72. Vernin C, Thenoz M, Pinatel C, Gessain A, Gout O, Delfau-Larue MH, Nazaret N, Legras-Lachuer C, Wattel E, Mortreux F. HTLV-1 bZIP factor HBZ promotes cell proliferation and genetic instability by activating OncomiRs. Cancer Res. 2014;74(21):6082-93.

73. Takiuchi Y, Kobayashi M, Tada K, Iwai F, Sakurada M, Hirabayashi S, Nagata K, Shirakawa K, Shindo K, Yasunaga JI, et al. HTLV-1 bZIP factor suppresses TDP1 expression through inhibition of NRF-1 in adult T-cell leukemia. Sci Rep. 2017;7(1):12849.

74. Kataoka K, Iwanaga M, Yasunaga JI, Nagata Y, Kitanaka A, Kameda T, Yoshimitsu M, Shiraishi Y, Sato-Otsubo A, Sanada M, et al. Prognostic relevance of integrated genetic profiling in adult T-cell leukemia/lymphoma. Blood. 2018;131(2):215-25.

75. Kataoka K, Nagata Y, Kitanaka A, Shiraishi Y, Shimamura T, Yasunaga J, Totoki Y, Chiba K, Sato-Otsubo A, Nagae G, et al. Integrated molecular analysis of adult T cell leukemia/lymphoma. Nat Genet. 2015;47(11):1304-15.

\section{Publisher's Note}

Springer Nature remains neutral with regard to jurisdictional claims in published maps and institutional affiliations.
Ready to submit your research? Choose BMC and benefit from:

- fast, convenient online submission

- thorough peer review by experienced researchers in your field

- rapid publication on acceptance

- support for research data, including large and complex data types

- gold Open Access which fosters wider collaboration and increased citations

- maximum visibility for your research: over $100 \mathrm{M}$ website views per year

At BMC, research is always in progress.

Learn more biomedcentral.com/submissions 